Research Article

\title{
Estimation of Wheelset Natural Vibration Characteristics Based on Transfer Matrix Method with Various Elastic Beam Models
}

\author{
Pengfei Liu $\mathbb{D}^{1,2}$ Hongjun Liu $\mathbb{D}^{2},{ }^{2}$ and Qing Wu $\mathbb{D}^{3}$ \\ ${ }^{1}$ State Key Laboratory of Mechanical Behavior and System Safety of Traffic Engineering Structures, \\ Shijiazhuang Tiedao University, Shijiazhuang 050043, China \\ ${ }^{2}$ School of Mechanical Engineering, Shijiazhuang Tiedao University, Shijiazhuang 050043, China \\ ${ }^{3}$ Centre for Railway Engineering, Central Queensland University, Rockhampton, Australia \\ Correspondence should be addressed to Pengfei Liu; lpfswjtu@163.com
}

Received 29 March 2021; Accepted 31 May 2021; Published 21 June 2021

Academic Editor: Traian Mazilu

Copyright (c) 2021 Pengfei Liu et al. This is an open access article distributed under the Creative Commons Attribution License, which permits unrestricted use, distribution, and reproduction in any medium, provided the original work is properly cited.

\begin{abstract}
The elastic vibration of the wheelset is a potential factor inducing wheel-rail defects. It is important to understand the natural vibration characteristics of the flexible wheelset for slowing down the defect growth. To estimate the elastic free vibration of the railway wheelset with the multidiameter axle, the transfer matrix method (TMM) is applied. The transfer matrices of four types of elastic beam models are derived including the Euler-Bernoulli beam, Timoshenko beam, elastic beam without mass and shearing stiffness, and massless elastic beam with shearing stiffness. For each type, the simplified model and detailed models of the flexible wheelset are developed. Both bending and torsional modes are compared with that of the finite element (FE) model. For the wheelset bending modes, if the wheel axle is modelled as the Euler-Bernoulli beam and Timoshenko beam, the natural frequencies can be reflected accurately, especially for the latter one. Due to the lower solving accuracy, the massless beam models are not applicable for the analysis of natural characteristics of the wheelset. The increase of the dividing segment number of the flexible axle is helpful to improve the modal solving accuracy, while the computation effort is almost kept in the same level. For the torsional vibration mode, it mainly depends on the axle torsional stiffness and wheel inertia rather than axle torsional inertia.
\end{abstract}

\section{Introduction}

Wheelsets are key moving components in the railway vehicle systems. Conventional rigid-body modeling methods only evaluate wheelset vibration characteristics in low frequency. However, many practical problems induced by wheel axle bending and torsional vibrations in the mid-high frequency domain have occurred frequently. These vibrations can be observed in all sorts of railway systems such as high-speed railways, subways, and heavy-haul railways. Some researchers have indicated that the rail corrugation, wheel-rail stick-slip vibration, and even wheel polygon wear are closely associated with wheelset elastic vibrations and track vibrations $[1,2]$, as shown in Figure 1. Therefore, it is very important to obtain the natural vibration characteristics of wheelsets so that the corresponding vibration isolation or control measures from the aspect of the railway vehicle can be proposed to alleviate the abnormal defects induced by the wheelset elastic vibration.

A number of methods can be used to solve the natural vibrating characteristics for elastic structures. Typical solving methods include finite element (FE) method and elastic vibration theory. Both of them have been widely used. To study the wheel-rail stick-slip problem in freight wagon systems, Sun and Simson [3] considered the three-directional translational degrees of freedom (DOF) of the wagon wheelset, when the roll, pitch, and yaw DOFs for each wheel were independent. Shen et al. [4] simplified the wheelset as two asymmetric parts connected by equivalent stiffness of the flexible wheel axle. The model then was applied to study the relations between rail corrugation and wheel-rail stick-slip 


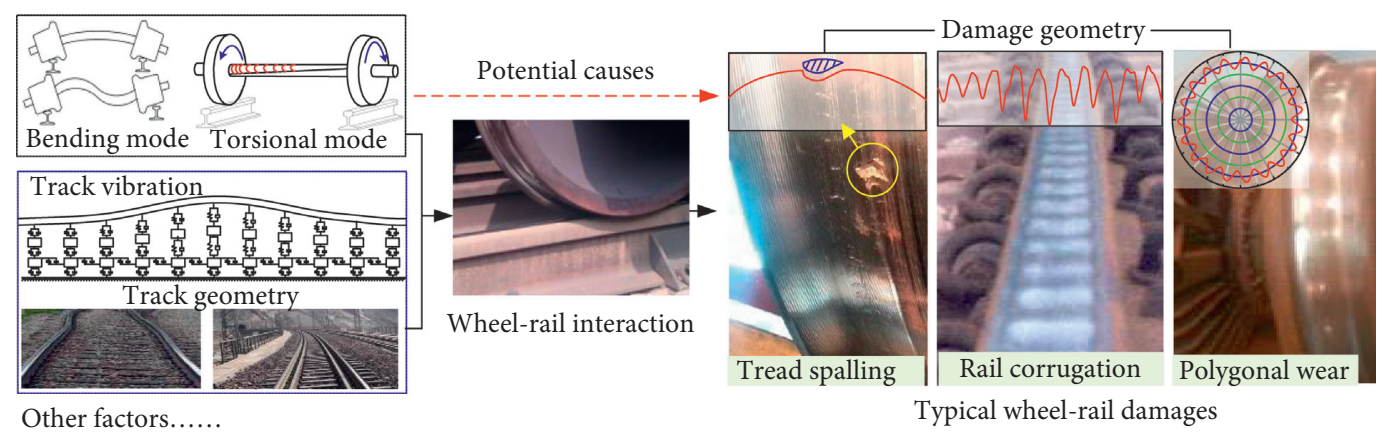

Figure 1: Potential influence of wheelset natural vibration on wheel-rail damage.

vibration. Chen et al. [5, 6] developed a wheelset-track coupled FE model and found that self-excited vibrations induced by the dynamic friction coefficient as well as the spring stiffness and damping of the sleeper supports both had important influences on rail corrugation formation and wheel polygonalization. Martínez-Casas et al. [7] combined a trajectory coordinate set with Eulerian modal coordinates to develop a model for a flexible wheelset running on a flexible curved track, which could be used to analyze the problems of rail corrugation or wheel polygonization. Guiral et al. [8] presented the formulation of a flexible rotating wheelset derived within the framework of a noninertial vehicle moving reference frame. Kaiser et al. [9] developed a vehicle-track model considering a FE submodel for a flexible wheelset and a wheel-rail contact model to research wheel-rail wear. Peng et al. [10] imported a FE model into a MBS (Multibody System) environment and found that, in some cases, the wheel polygonization order would be closely related to wheelset torsional modal frequency and vehicle speed. By investigating the harmonic response of wheelsets based on the FE analysis method, Cruceanu and Sorohan [11] identified how wheelrail system parameters affected the levels of vibrations and rolling noise. Based on an Eulerian approach and FE method, Baeza et al. [12] proposed three formulations which were then proved to be suitable for researching the coupled dynamics between wheelset (elastic) and track. As the first-order asymmetric bending mode of the wheelset occurred, Fourie et al. [13] found that the mode-coupling instability of traction motor pitching mode and wheelset torsion might induce the railhead corrugation. Ding et al. [14] established a FE model of a wheelset to study the relations between mode-coupling and falling-friction mechanisms. The model could be used to assess the curve squeal phenomenon in the railway system. Giner-Navarro et al. [15] also considered the interaction between a single-flexible-rotatory wheelset and elastic track to investigate the influence of wheel-rail stick-slip vibration on wheel squeal. Also, the linear vibration theory was applied to establish the flexible wheelset model with concentrated mass and moment of inertia [16]. Recently, the transfer matrix method has been widely used to solve the vibrations of pipe structure [17], tapered beam [18], masonry walls [19], and even missile systems [20]. The relevant method for flexible body vibration simulation could be introduced into the railway vehicle system and even the vehicle-track coupled model [21] or train-track dynamic model [22].
Compared with other methods, the TMM has the advantages of simple programming, modularized establishment of vibration equation, and fast numerical calculation. However, the application of TMM in wheelset dynamics for different elastic-beam models has not been reported. How about the modal solving accuracy of wheelset models with different elastic beams? Is it necessary to consider the axle rotational inertia in wheelset torsional vibration? What are the influences of the vibration mass, shear stiffness, and number of wheel axle dividing segments on the natural vibration characteristics? Solving the above problems is of great significance for putting forward a scientific modeling scheme for the axle-disc system similar to the wheelset. In this paper, wheelsets with the multidiameter axle will be studied. They can be regarded as combination systems composed by rigid wheels and flexible axles. Axle bending vibration can be solved using various methods including the Timoshenko beam, Euler-Bernoulli beam, and massless elastic beam with or without shearing stiffness. The torsional vibration can also be solved by the elastic axle models with or without mass. Another point investigated in this paper is that what are the differences among various axle modeling methods in analyzing wheelset natural vibrations? A typical freight wagon wheelset will be used as an example. The transfer matrices for different elastic beam models are derived and then applied to calculate wheelset natural vibration characteristics. The corresponding FE models are also developed to verify the theoretical analysis results and examine the solving accuracies of different transfer matrix models.

\section{Transfer Matrix of Flexible Axle with Mass for Wheelset}

For an actual wagon wheelset, as shown in Figure 2, it includes a multidiameter axle and two wheels with $S$ shape wheel disk. These three parts are assembled by interference fit. From the perspective of the construct composition, the multidiameter axle can be regarded as axle segments with different diameters and lengths, as shown in Figure 3, where the main structure parameters are also given according to the railway standard of [23]. The wheels and axles are mainly applied in heavy-haul railway vehicles with $27 \mathrm{t}$ and $30 \mathrm{t}$ axle load in China. Comparatively, the wheels are more rigid with heavier masses so that they can be treated as the nondeformable rigid bodies in simulations. Then, the main task 


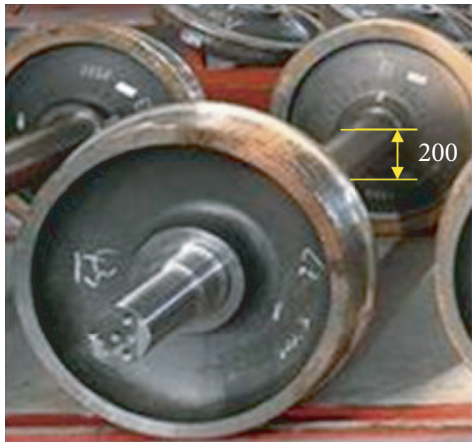

(a)

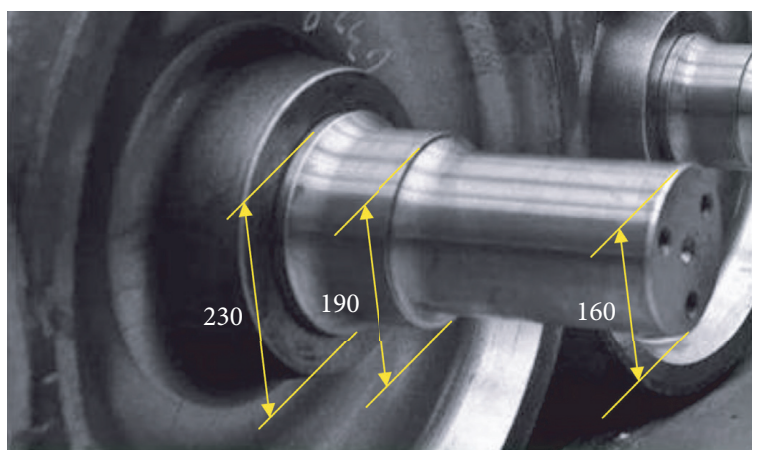

(b)

FIGURE 2: Freight wagon wheelset with the multidiameter axle.

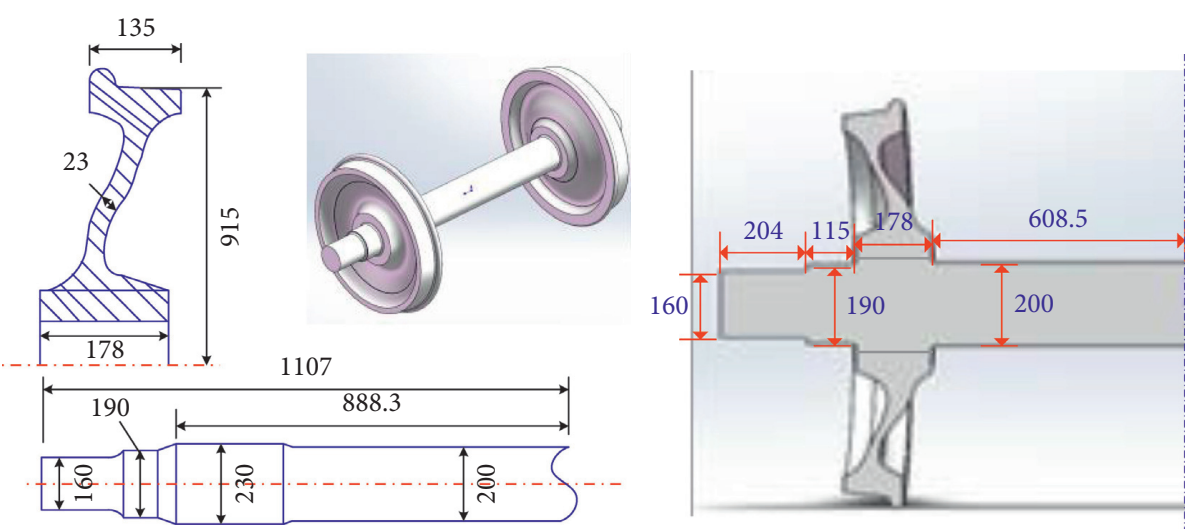

FIgURE 3: Wheelset structure and dimensions of the heavy-haul freight wagon.

for the study is to define the transfer matrix of the elastic axle segment.

For an axle with mass, the transfer matrix can be obtained by solving the vibration equations of an elastic beam. There are two typical beam theories for this case, i.e., Euler-Bernoulli beam and Timoshenko beam. The former does not consider the influence of rotational inertia and shear deformation whilst the latter does. Taking an infinitesimal axle segment as example (Figure 4), its rotational angle $\theta$ includes the components of $\alpha$ (induced by moment) and $\beta$ (induced by shearing force). In the Euler-Bernoulli beam, only the angle $\alpha$ is considered, which neglects the effect of rotational inertial $I_{\text {rot }}$. In the Timoshenko beam theory, the factor $I_{\text {rot }}$ and both the deflection angles of $\alpha$ and $\beta$ are considered. Introducing the linear density $\rho$ of the axle and inertial radius $r_{\mathrm{g}}$, the inertial $I_{\text {rot }}$ can then be defined as $I_{\text {rot }}=\rho r_{\mathrm{g}}{ }^{2}$. The force states of the bending moment $M$ and shearing force $Q$ in the left and right sides of the element are also displayed in Figure 4(b).

For the axle segment, the vibration differential equation and force equilibrium relations can be deduced easily, which will not be explained in this paper. On this basis, the vibration equations of Euler-Bernoulli beam and Timoshenko beam can be expressed as equations (1) and (2), respectively, according to the vibration theory [24]:

$$
E I \frac{\partial^{4} y}{\partial x^{4}}+\rho \frac{\partial^{4} y}{\partial t^{2}}=0
$$

$$
\frac{\partial^{4} y}{\partial x^{4}}+\frac{\rho}{E I} \frac{\partial^{2} y}{\partial t^{2}}-\frac{\rho r_{g}^{2}}{E I} \frac{\partial^{4} y}{\partial x^{2} \partial t^{2}}+\frac{\rho}{G A}\left(\frac{\rho r_{g}^{2}}{E I} \frac{\partial^{2} y}{\partial t^{4}}-\frac{\partial^{4} y}{\partial x^{2} \partial t^{2}}\right)=0
$$

where $y$ and $x$ are the deflection and length, $E$ and $G$ represent the elastic modulus and shearing modulus, and $I$ and $A$ denote the inertia moment and the cross-sectional area, which are the functions of the sectional dimensions.

Introduce the mathematic expression of deflection $y(x, t)$ in modal coordinates as

$$
y(x, t)=Y(x) e^{i \omega t}
$$

where $Y(x)$ and $\omega$ are mode shape and angular frequency, respectively.

Then, equations (1) and (2) can be rewritten as 


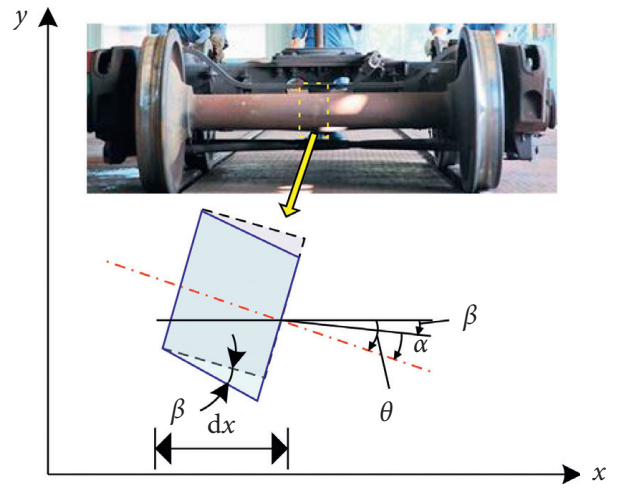

(a)

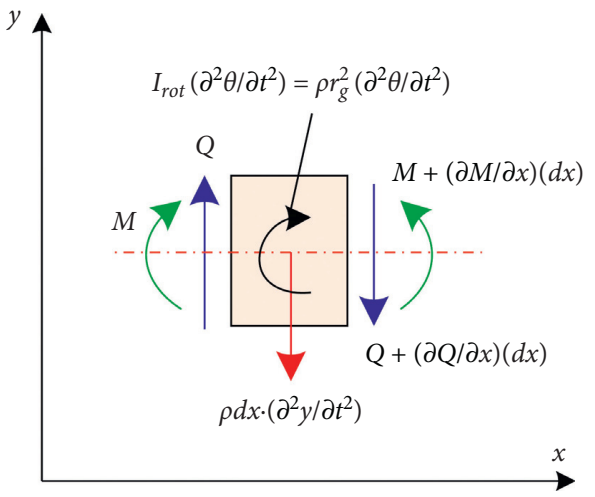

(b)

FIGURE 4: Force state of the flexible axle segment for the wheelset axle. (a) Flexible axle segment. (b) Force state.

$$
\begin{aligned}
& \qquad \begin{array}{l}
\frac{\mathrm{d}^{4} Y(x)}{\mathrm{d} x^{4}}-\frac{\rho \omega^{2}}{E I} Y(x)=0, \\
\frac{\mathrm{d}^{4} Y(x)}{\mathrm{d} x^{4}}+\frac{\rho \omega^{2}}{E I}\left(\frac{E I}{G A}+r_{g}^{2}\right) \frac{\mathrm{d}^{2} Y(x)}{\mathrm{d} x^{2}}-\frac{\rho \omega^{2}}{E I}\left(1-\frac{\rho r_{g}^{2} \omega^{2}}{G A}\right) Y(x)=0 .
\end{array} \\
& \begin{array}{l}
\text { The general solution of equation } \quad(4) \text { for the } \\
\lambda_{1,2}=\sqrt{\sqrt{\varsigma^{4}+\frac{1}{4}(\kappa-\tau)^{2}}+\frac{1}{2}(\kappa+\tau)} \\
\kappa=\frac{\rho \omega^{2}}{(G A)} \\
\gamma=\sqrt[4]{\frac{\rho \omega^{2}}{E I}}
\end{array} \\
& \left\{\begin{array}{l}
Y(x)=A \cosh \gamma x+B \sinh \gamma x+C \cos \gamma x+D \sin \gamma x, \\
\tau=\frac{\rho r_{g}^{2} \omega^{2}}{(E I)}
\end{array}\right. \\
& \left\{=\sqrt[4]{\frac{\rho \omega^{2}}{E I}}\right.
\end{aligned}
$$

Correspondingly, the general solution of equation (5) for the Timoshenko beam can be expressed as [24]

In the modal coordinates, the state parameters of $\Theta, M$, $Q$, and $Y$ satisfy the relations given below:

$$
\begin{cases}\Theta=\frac{\mathrm{d} Y}{\mathrm{~d} x}, M=E I \frac{\mathrm{d} \Theta}{\mathrm{d} x}, Q=\frac{\mathrm{d} M}{\mathrm{~d} x}, & \text { (for Euler-Bernoulli beam), } \\ \Theta=\frac{\mathrm{d} Y}{\mathrm{~d} x}-\frac{\mathrm{Q}}{G A}, M=E I \frac{\mathrm{d} \Theta}{\mathrm{d} x}, Q=\frac{\mathrm{d} M}{\mathrm{~d} x}+\rho r^{2} \omega^{2} \Theta, & \text { (for Timoshenko beam). }\end{cases}
$$

The next key point is to determine the unknown coefficients $A, B, C$, and $D$ for equations (6) and (7). Taking the Timoshenko beam as an example, combining equations (7) and (8), the state vector $\mathbf{Z}(x)$ in the axle segment can be expressed as

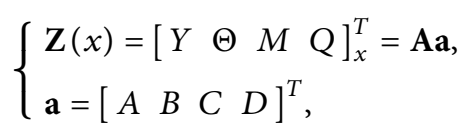

where $\mathbf{A}$ is the transitional matrix which has the formation as given below: 


$$
\mathbf{A}=\left[\begin{array}{cccc}
\cosh \lambda_{1} x & \sinh \lambda_{1} x & \cos \lambda_{2} x & \sin \lambda_{2} x \\
\frac{P_{1}}{\lambda_{1}} \sin h \lambda_{1} x & \frac{P_{1}}{\lambda_{1}} \cos \lambda_{1} x & \frac{P_{2}}{\lambda_{2}} \sin \lambda_{2} x & -\frac{P_{2}}{\lambda_{2}} \cos \lambda_{2} x \\
P_{1} E I \cosh \lambda_{1} x & P_{1} E I \sinh \lambda_{1} x & P_{2} E I \cos \lambda_{2} x & P_{2} E I \sin \lambda_{2} x \\
\frac{\rho \omega^{2}}{\lambda_{1}} \sinh \lambda_{1} x & \frac{\rho \omega^{2}}{\lambda_{1}} \cosh \lambda_{1} x & \frac{\rho \omega^{2}}{\lambda_{2}} \sin \lambda_{2} x & -\frac{\rho \omega^{2}}{\lambda_{2}} \cos \lambda_{2} x
\end{array}\right],
$$

where $P_{1}=\kappa+\lambda_{1}^{2}$ and $P_{2}=\kappa-\lambda_{2}^{2}$.

In free boundary conditions, the sate vector for $x=0$ can be calculated as

$$
\begin{aligned}
\mathbf{Z}(0) & =\left[\begin{array}{llll}
Y & \Theta & M & Q
\end{array}\right]_{x=0}^{T}, \\
& =\mathbf{A}_{x=0} \mathbf{a} .
\end{aligned}
$$

Hereby, the column matrix a can be determined by

$$
\mathbf{a}=\mathbf{A}_{x=0}^{-1}\left[\begin{array}{llll}
Y & \Theta & M & Q
\end{array}\right]_{x=0}^{T} .
$$

$$
\mathbf{H}=\left[\begin{array}{cc}
-P_{2} \cosh \lambda_{1} l+P_{1} \cos \lambda_{2} l & \lambda_{1} \sin h \lambda_{1} l+\lambda_{2} \sin \lambda_{2} l \\
-P_{1} P_{2}\left(\frac{\sin h \lambda_{1} l}{\lambda_{1}}-\frac{\sin \lambda_{2} l}{\lambda_{2}}\right) & P_{1} \cosh \lambda_{1} l-P_{2} \cos \lambda_{2} l \\
-P_{1} P_{2} E I\left(\cosh \lambda_{1} l-\cos \lambda_{2} l\right) & E I\left(P_{1} \lambda_{1} \sinh \lambda_{1} l+P_{2} \lambda_{2} \sin \lambda_{2} l\right) \\
-\frac{P_{2} \rho \omega^{2}}{\lambda_{1}} \sinh \lambda_{1} l+\frac{P_{1} \rho \omega^{2}}{\lambda_{2}} \sin \lambda_{2} l & \rho \omega^{2}\left(\cosh \lambda_{1} l-\cos \lambda_{2} l\right)
\end{array}\right.
$$

For equations (6) and (8), the derivations follow the same calculation procedures as above. The transfer matrix of the Euler-Bernoulli beam can be expressed as

$$
\mathbf{H}=\left[\begin{array}{cccc}
S(\gamma l) & \frac{T(\gamma l)}{\gamma} & \frac{U(\gamma l)}{E I \gamma^{2}} & \frac{V(\gamma l)}{E I \gamma^{3}} \\
\gamma V(\gamma l) & S(\gamma l) & \frac{T(\gamma l)}{E I \gamma} & \frac{U(\gamma l)}{E I \gamma^{2}} \\
E I \gamma^{2} U(\gamma l) & E I \gamma V(\gamma l) & S(\gamma l) & \frac{T(\gamma l)}{\gamma} \\
E I \gamma^{3} T(\gamma l) & E I \gamma^{2} U(\gamma l) & \gamma V(\gamma l) & S(\gamma l)
\end{array}\right],
$$

where $S, T, U$, and $V$ can be expressed as
So the state vector in position $x=l$ is

$$
\begin{aligned}
\mathbf{Z}(l) & =\left[\begin{array}{llll}
Y & \Theta & M & Q
\end{array}\right]_{x=l}^{T}, \\
& =\mathbf{A}_{x=l} \mathbf{A}_{x=0}^{-1}\left[\begin{array}{llll}
Y & \Theta & M & Q
\end{array}\right]_{x=0}^{T}, \\
& =\mathbf{H}\left[\begin{array}{llll}
Y & \Theta & M & Q
\end{array}\right]_{x=0}^{T},
\end{aligned}
$$

where $\mathbf{H}=\mathbf{A}_{x=1} \mathbf{A}_{x=0}^{-1}$ represents the transfer matrix of the Timoshenko beam. The transfer matrix is expressed as [25]

$$
\left.\begin{array}{cc}
\frac{\cos h \lambda_{1} l-\cos \lambda_{2} l}{E I} & -\frac{\lambda_{1} P_{2}}{\rho \omega^{2}} \sin h \lambda_{1} l-\frac{\lambda_{2} P_{1}}{\rho \omega^{2}} \sin \lambda_{2} l \\
\frac{P_{1}}{E I \lambda_{1}} \sin h \lambda_{1} l-\frac{P_{2}}{E I \lambda_{2}} \sin \lambda_{2} l & -\frac{P_{1} P_{2}}{\rho \omega^{2}}\left(\cosh \lambda_{1} l-\cos \lambda_{2} l\right) \\
P_{1} \cos h \lambda_{1} l-P_{2} \cos \lambda_{2} l & -\frac{P_{1} P_{2} E I}{\rho \omega^{2}}\left(\lambda_{1} \sin h \lambda_{1} l+\lambda_{2} \sin \lambda_{2} l\right) \\
\frac{\rho \omega^{2}}{E I}\left(\frac{\sin h \lambda_{1} l}{\lambda_{1}}-\frac{\sin \lambda_{2} l}{\lambda_{2}}\right) & -P_{2} \cosh \lambda_{1} l+P_{1} \cos \lambda_{2} l
\end{array}\right]
$$

$$
\left\{\begin{array}{l}
S(\gamma l)=\frac{[\cosh (\gamma l)+\cos (\gamma l)]}{2}, \\
T(\gamma l)=\frac{[\sinh (\gamma l)+\sin (\gamma l)]}{2}, \\
U(\gamma l)=\frac{[\cosh (\gamma l)-\cos (\gamma l)]}{2}, \\
V(\gamma l)=\frac{[\sinh (\gamma l)-\sin (\gamma l)]}{2} .
\end{array}\right.
$$

\section{Transfer Matrix of Flexible Axle without Mass}

In some axle-disc type components, the axle can also be assumed as a massless elastic axle. The massless axle provides the main deformation energy but little inertial energy. If the axle vibrating mass is not taken into account, the force and 
displacement states at the input and output ends of the massless elastic beam have the relations, as shown in Figure 5, where $i$ denotes the $i$ th axle segment.

The elastic deformation and force conditions can be described by structural mechanics according to the deformation compatibility principle. The transfer relations can be expressed as

$$
\left\{\begin{array}{l}
y_{i, i+1}=y_{i-1, i}+l_{i} \theta_{i-1, i}+\frac{l_{i}^{2}}{2 E I_{i}} M_{i-1, i}+\frac{l_{i}^{3}}{6 E I_{i}} Q_{i-1, i} \\
\theta_{i, i+1}=\theta_{i-1, i}+\frac{l_{i}^{2}}{E I_{i}} M_{i-1, i}+\frac{l_{i}^{2}}{2 E I_{i}} Q_{i-1, i} \\
M_{i, i+1}=M_{i-1, i}+l_{i} Q_{i-1, i} \\
Q_{i-1, i}=Q_{i-1, i} .
\end{array}\right.
$$

Changing the formation of equation (17) to a matrix form, the transfer matrix of the massless flexible axle is then obtained as given in equation (18). On this basis, if the shearing stiffness of the axle is considered, equation (18) will be rewritten as equation (19):

$$
\begin{aligned}
\mathbf{H} & =\left[\begin{array}{cccc}
1 & l_{i} & \frac{l_{i}^{2}}{\left(2 E I_{i}\right)} & \frac{l_{i}^{3}}{\left(6 E I_{i}\right)} \\
0 & 1 & \frac{l_{i}}{\left(E I_{i}\right)} & \frac{l_{i}^{2}}{\left(2 E I_{i}\right)} \\
0 & 0 & 1 & l_{i} \\
0 & 0 & 0 & 1
\end{array}\right], \\
\mathbf{H} & =\left[\begin{array}{cccc}
1 & l_{i} & \frac{l_{i}^{2}}{\left(2 E I_{i}\right)} & \frac{l_{i}^{3}}{\left(6 E I_{i}\right)}-\frac{l_{i}}{(G A)} \\
0 & 1 & \frac{l_{i}}{\left(E I_{i}\right)} & \frac{l_{i}^{2}}{\left(2 E I_{i}\right)} \\
0 & 0 & 1 & l_{i} \\
0 & 0 & 0 & 1
\end{array}\right] .
\end{aligned}
$$

Therefore, equations (14), (15), (18), and (19), respectively, represent the transfer matrices of the (a) Euler-Bernoulli beam, (b) Timoshenko beam, (c) elastic beam without mass and shearing stiffness, and (d) the massless elastic beam with shearing stiffness.

\section{Wheelset Bending Vibration Model Based on Transfer Matrix}

For the modeling of a flexible wheelset, the model can be divided into the elastically deformable part of axle segments and the nondeformable part of wheels. The rigid wheels are

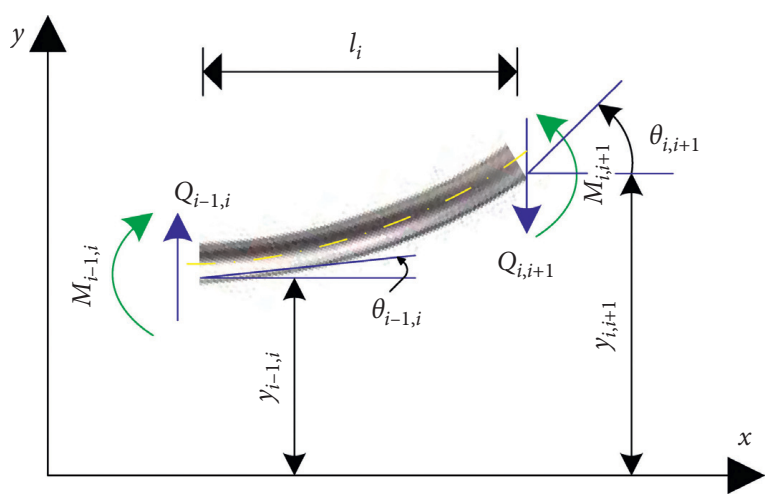

Figure 5: Force and deformation states of the massless beam element.

connected by the flexible axle with or without the vibrating mass. For the rigid wheel, its force and displacement state parameters at both sides are shown in Figure 6. The vertical displacements and rotation angle at the left side of the lumped mass are in accordance with those at the wheel right side, as expressed in equation (20). The transferring relations of bending moment and shearing force should consider the influence of inertia effect. According to the dynamic equilibrium relation, the vibration differential equations can be expressed as equation (21).

$$
\begin{aligned}
& \left\{\begin{array}{l}
y_{i, i+1}=y_{i, i-1}, \\
\theta_{i, i+1}=\theta_{i, i-1},
\end{array}\right. \\
& \left\{\begin{array}{l}
M_{z i, i+1}=M_{z i, i-1}+J_{w} \theta=M_{z i, i-1}-J_{w} \omega^{2} \Theta, \\
Q_{i, i+1}=Q_{i, i-1}-m_{w} y=Q_{i, i-1}+m_{w} \omega^{2} Y,
\end{array}\right.
\end{aligned}
$$

where $J_{w}$ and $m_{w}$ are the rotational inertia and mass of the wheel, respectively. By changing equations (20) and (21) into the matrix in the modal coordinate frame as below, the transfer matrix of the wheel can then be calculated by $\mathbf{H}_{w}$ :

$$
\begin{aligned}
{\left[\begin{array}{c}
Y \\
\Theta \\
M \\
Q
\end{array}\right]_{i, i+1} } & =\left[\begin{array}{cccc}
1 & 0 & 0 & 0 \\
0 & 1 & 0 & 0 \\
0 & -J_{w} \omega^{2} & 1 & 0 \\
m_{w} \omega^{2} & 0 & 0 & 1
\end{array}\right]\left[\begin{array}{c}
Y \\
\Theta \\
M \\
Q
\end{array}\right]_{i, i-1}, \\
& =H_{w}\left[\begin{array}{c}
Y \\
\Theta \\
M
\end{array}\right]_{i, i-1} .
\end{aligned}
$$

Two modeling schemes are proposed for the wheelset, as shown in Figure 7 . The numbers denote the sequence of wheelset components. Scheme A is a model that includes two wheels connected by three segments of flexible axles. In this model, the diameters of all axle segments are assumed to be the same. The other one, i.e., scheme B, is a detailed model with two rigid wheels connected by 9 segments of nonuniform flexible axles. In scheme B, the wheels are treated as 


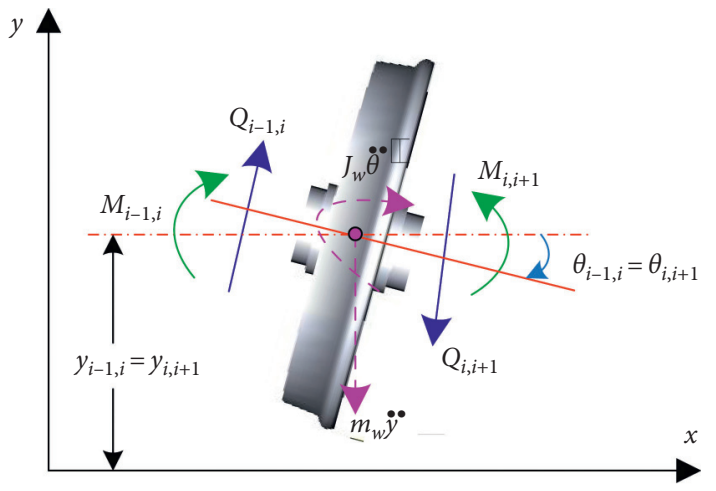

FIgURE 6: Force analysis of the rigid wheel.

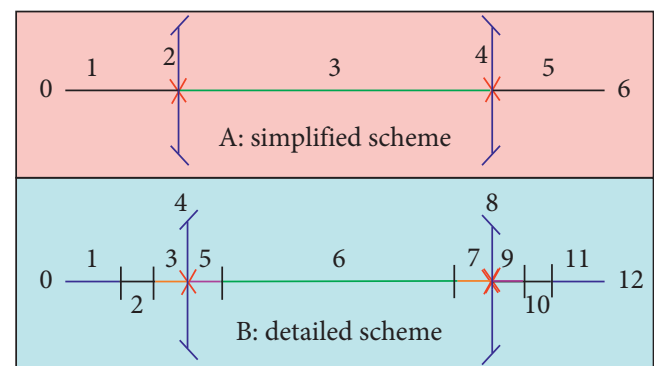

Figure 7: Wheelset and its dynamic model of the piecewise flexible axle.

a lumped mass located at the center of the wheel hub. 0 represents the left boundary, while 6 and 12 denote the right boundaries in schemes $A$ and $B$, respectively.

For the modeling schemes $\mathrm{A}$ and $\mathrm{B}$, the corresponding transfer relations of state vectors from the left boundary to the right boundary can be calculated, respectively, by the following equations:

$$
\begin{aligned}
\mathbf{Z}_{6,5} & =\mathbf{H}_{T} \mathbf{Z}_{0,1}=\mathbf{H}_{5} \mathbf{H}_{4} \mathbf{H}_{3} \mathbf{H}_{2} \mathbf{H}_{1} \mathbf{Z}_{0,1}, \\
\mathbf{Z}_{12,11} & =\mathbf{H}_{T} \mathbf{Z}_{0,1}=\mathbf{H}_{11} \mathbf{H}_{10} \mathbf{H}_{9} \mathbf{H}_{8} \mathbf{H}_{7} \mathbf{H}_{6} \mathbf{H}_{5} \mathbf{H}_{4} \mathbf{H}_{3} \mathbf{H}_{2} \mathbf{H}_{1} \mathbf{Z}_{0,1},
\end{aligned}
$$

where $\mathbf{H}_{T}$ is the global transfer matrix. $\mathbf{H}_{2}$ and $\mathbf{H}_{4}$ in equation (23) and $\mathbf{H}_{4}$ and $\mathbf{H}_{8}$ in equation (24) refer to the matrix $\mathbf{H}_{w}$ in equation (22). The other matrices can be selected uniformly within equations (14), (15), (18), and (19) according to different elastic beam assumptions. It should be noted that, if the wheelset symmetries are taken into account, the computational efficiency is hopeful to be improved further. But the wheelset in the locomotive or motor vehicle has the asymmetric structures due to the gearbox. The mentioned wheelsets have the similar problem size and solving process. In this paper, the wagon wheelset is just taken as a typical example of railway wheelsets to examine the effectiveness and efficiency of TMM in the solution of natural vibration.

Using the assumption of free boundary condition, the shearing force and moments at left and right ends can be regarded as zero. Equation (24) can be further transformed as

$$
\left[\begin{array}{c}
Y \\
\Theta \\
0 \\
0
\end{array}\right]_{11,12}=\mathbf{H}_{T}\left[\begin{array}{c}
Y \\
\Theta \\
0 \\
0
\end{array}\right]_{0,1}=\left[\begin{array}{llll}
h_{11} & h_{12} & h_{13} & h_{14} \\
h_{21} & h_{22} & h_{23} & h_{24} \\
h_{31} & h_{32} & h_{33} & h_{34} \\
h_{41} & h_{42} & h_{43} & h_{44}
\end{array}\right]\left[\begin{array}{c}
Y \\
\Theta \\
0 \\
0
\end{array}\right]_{0,1} .
$$

From equation (25), a homogeneous equation can be found, which has the formation as

$$
\left[\begin{array}{l}
0 \\
0
\end{array}\right]_{11,12}=\left[\begin{array}{ll}
h_{31} & h_{32} \\
h_{41} & h_{42}
\end{array}\right]\left[\begin{array}{l}
Y \\
\Theta
\end{array}\right]_{0,1}
$$

For a vibration system, there should be nonzero solutions in equation (26), which means the determinant of the coefficient matrix equals zero. Therefore, the frequency equations $f(\omega)$ can be expressed as

$$
f(\omega)=\left|\begin{array}{ll}
h_{31} & h_{32} \\
h_{41} & h_{42}
\end{array}\right|=0
$$

The zero solutions of equation (27) correspond to the natural frequencies of the vibration system. The next task is to analyze the mode shapes. In the free boundary condition, if the vertical displacement of the left end is defined as $Y_{0,1}=1$ in equation (26), then the other state parameter of rotation angle $\Theta$ can be calculated by

$$
\Theta_{0,1}=-\frac{h_{31}}{h_{32}}=-\frac{h_{41}}{h_{42}} .
$$

Then, the boundary condition can be expressed as

$$
\mathbf{Z}_{0,1}=\left[1, \Theta_{0,1}, 0,0\right]^{T} .
$$

Finally, introducing $\mathbf{Z}_{0,1}$ into equations (23) and (24), the state vectors of any point in the wheelset can be calculated by the their corresponding transfer matrices.

\section{Wheelset Torsional Vibration Model}

Following the modeling principle of TMM, the wheelset torsion vibration model can be simplified as a combined system of rigid wheels and torsional flexible axles, as shown in Figure 8, where $\phi_{i-1, i}$ and $T_{i-1, i}$ are the torsion angle and torque in the left side of $i$ th element. The external torque and inertia moment determine the system dynamic characteristics.

The rigid wheel has only the torsional DOF. The torsional angle and torque at the left side of the lumped mass are in accordance with those of wheel right side. The effect of wheel inertia should be taken into account in the torsional vibration equation. Transforming the torsional displacement into the form of modal coordinate as $\phi=\Phi e^{i \omega t}$, then the transfer matrix $\mathbf{R}_{w}$ of the wheels can be deduced as follows:

$$
\left[\begin{array}{c}
\Phi \\
T
\end{array}\right]_{i-1, i}=\left[\begin{array}{cc}
1 & 0 \\
-\omega^{2} I_{w} & 1
\end{array}\right]\left[\begin{array}{c}
\Phi \\
T
\end{array}\right]_{i-1, i}=\mathbf{R}_{w}\left[\begin{array}{c}
\Phi \\
T
\end{array}\right]_{i, i+1}
$$

With the same solving procedure described in Section 2 and the assumption of free boundary conditions, it is not 


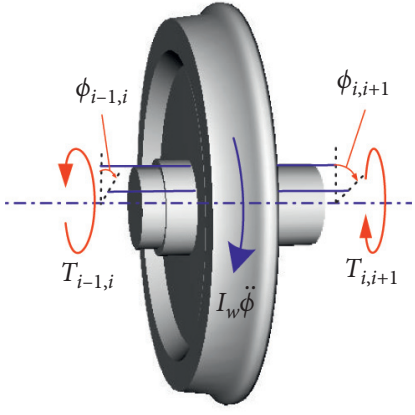

(a)

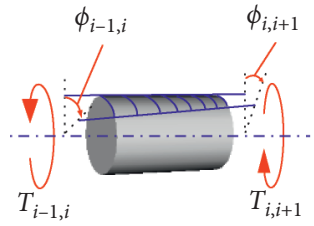

(b)

Figure 8: Wheelset torsional vibration models of the wheel and flexible axle. (a) Rigid wheel. (b) Flexible axle segment.

difficult to develop the transfer relation for the flexible axle with the mass [25]:

$$
\left[\begin{array}{c}
\Phi \\
T
\end{array}\right]_{i, i+1}=\left[\begin{array}{cc}
\cos \varepsilon l & \frac{1}{\varepsilon G I_{p}} \sin \varepsilon l \\
-\varepsilon G I_{p} \sin \varepsilon l & \cos \varepsilon l
\end{array}\right]\left[\begin{array}{l}
\Phi \\
T
\end{array}\right]_{i-1, i}=\mathbf{S}\left[\begin{array}{c}
\Phi \\
T
\end{array}\right]_{i-1, i},
$$

where $I_{p}$ is the polar moment of inertia determined by the axle cross-section dimensions.

From another perspective, in some applications, the axle can be regarded as a massless flexible axle with the transfer relations as

$$
\left[\begin{array}{c}
\Phi \\
T
\end{array}\right]_{i, i+1}=\left[\begin{array}{cc}
1 & \frac{1}{G I_{p}} \\
0 & 1
\end{array}\right]\left[\begin{array}{l}
\Phi \\
T
\end{array}\right]_{i-1, i}=\mathbf{U}\left[\begin{array}{l}
\Phi \\
T
\end{array}\right]_{i-1, i}
$$

In the torsional vibration simulations, $\mathbf{S}$ and $\mathbf{U}$ are the transfer matrices of the flexible axle with and without the distributing mass, respectively. Under the boundary condition of $\mathbf{X}_{0,1}$ as given in equation (33), the corresponding transfer matrices of the simplified and detailed models in Figure 7 can be expressed as equations (34) and (35), respectively. Different transfer relations of the torsional axle with and without the mass can be developed by replacing $\mathbf{S}_{i}$ by $\mathbf{U}_{i}$ :

$$
\begin{aligned}
\mathbf{X}_{0,1} & =[1,0]^{T}, \\
\mathbf{X}_{6,5} & =\mathbf{S}_{T} \mathbf{X}_{0,1}=\mathbf{S}_{5} \mathbf{S}_{4} \mathbf{S}_{3} \mathbf{S}_{2} \mathbf{S}_{1} \mathbf{X}_{0,1}, \\
\mathbf{X}_{12,11} & =\mathbf{S}_{T} \mathbf{X}_{0,1}=\mathbf{S}_{11} \mathbf{S}_{10} \mathbf{S}_{9} \mathbf{S}_{8} \mathbf{S}_{7} \mathbf{S}_{6} \mathbf{S}_{5} \mathbf{S}_{4} \mathbf{S}_{3} \mathbf{S}_{2} \mathbf{S}_{1} \mathbf{X}_{0,1},
\end{aligned}
$$

where $\mathbf{S}_{T}$ is the global transfer matrix. $\mathbf{S}_{2}$ and $\mathbf{S}_{4}$ in equation (34) and $\mathbf{S}_{4}$ and $\mathbf{S}_{8}$ in equation (35) refer to the matrix $\mathbf{R}_{\mathrm{w}}$ in equation (30). The other matrices can be selected uniformly within equations (31) and (32) according to different flexible axle assumptions.

\section{Solutions of Wheelset Natural Frequencies and Vibration Modes}

To solve the natural vibration characteristics of the wheelset in Figure 3, the transfer methods are applied in its modeling schemes. The elastic beams of Euler-Bernoulli beam (EB), Timoshenko beam (TB), elastic beam without mass and shearing stiffness (Mless-B), and the massless elastic beam with shearing stiffness (Mless-BwS) are used in the modal analysis so that the influences of modeling schemes and beam models on the simulated free-vibration characteristics can be evaluated simultaneously. The material property parameters of the wheelset are given in Table 1.

6.1. Solution of Bending Vibration Modes. The natural frequencies of the flexible wheelset correspond to the nonzero solutions of equation (27), which can be solved numerically by the bisection method. In order to reveal the differences in detail between the solution curves of different models, the $\omega-f(\omega)$ curve is drawn and compared, as shown in Figure 9, by taking a search frequency with the step as small as possible. What we focus on is the abscissa values of intersection points between the solution curve and zero axis. The intersection coordinate corresponds to the natural frequencies. The first solution of 0 Hertz represents the rigid motion frequency. As the frequency rises, the frequency of 1st-order bending mode appears firstly. In the simplified model, the natural frequencies of the 1st-order bending mode for EB, Mless-B, Mless-BwS, and TB correspond to $126 \mathrm{~Hz}, 163 \mathrm{~Hz}, 163 \mathrm{~Hz}$, and $124 \mathrm{~Hz}$, respectively, while they change to $123 \mathrm{~Hz}, 163 \mathrm{~Hz}, 163 \mathrm{~Hz}$, and $120 \mathrm{~Hz}$ in the detailed model. In the massless beam (Mless-B and Mless-BwS) conditions, no difference of the natural frequencies can be observed between the simplified and detailed models. This means that the pure shearing stiffness of the wheel axle has the marginal effect on wheelset natural vibrations. Compared with the results of the Euler-Bernoulli and Timoshenko beams, the bending frequencies of the massless beam system may increase by about $40 \mathrm{~Hz}$, no matter in the simplified model or the detailed model. The natural frequencies based on the Timoshenko beam decreases by 2$3 \mathrm{~Hz}$ relative to those calculated by the Euler-Bernoulli beam 
TABLE 1: Main material property parameters of wheelset.

\begin{tabular}{lcccccc}
\hline Wheel type & Axle type & Material & Elasticity modulus & Shear modulus & Density & Poisson's ratio \\
\hline HFS & RF2 & Alloy steel & $2.06 e 11 \mathrm{~N} / \mathrm{m}^{2}$ & $0.794 e 11 \mathrm{~N} / \mathrm{m}^{2}$ & $7800 \mathrm{~kg} / \mathrm{m}^{3}$ & 0.3 \\
\hline
\end{tabular}

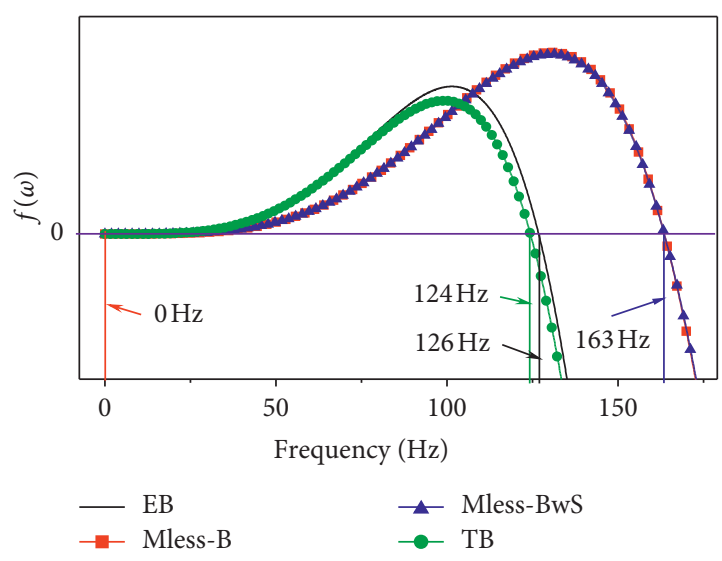

(a)

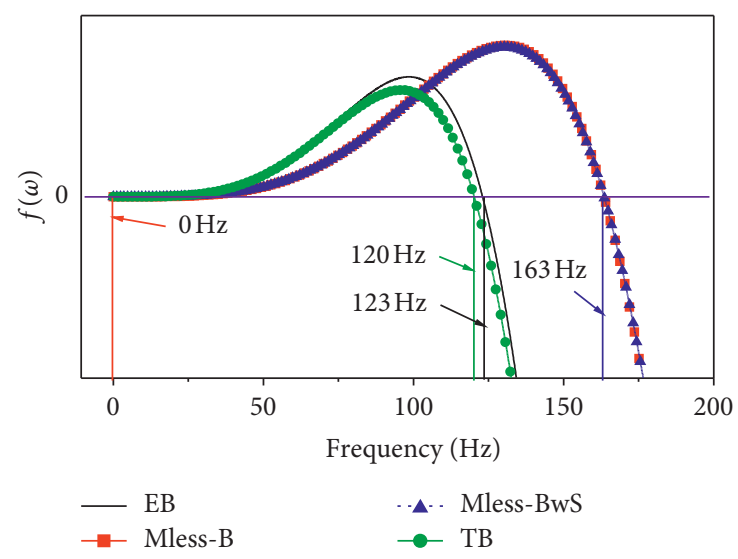

(b)

Figure 9: Solution curves of 1st-order bending for different modeling schemes. (a) Simplified model. (b) Detailed mode.

theory. The corresponding mode shapes are compared in Figure 10. The 1st-order mode shape presents as the bending vibration relative to the wheelset geometric center. The vibration modes in all modeling schemes follow the same shape, but the differences in the mode shape mainly depends on whether the beam mass is considered. In the simplified and detailed models, the mentioned differences reach about $14 \%$ and $10.5 \%$, respectively.

As the frequency increases, the modal frequency of 2ndorder bending can be found, as shown in Figure 11. The corresponding natural frequencies of EB, Mless-B, Mless$\mathrm{BwS}$, and TB models obtained from the simplified scheme are $267 \mathrm{~Hz}, 298 \mathrm{~Hz}, 292 \mathrm{~Hz}$, and $257 \mathrm{~Hz}$, respectively, which will correspondingly change as $262 \mathrm{~Hz}, 298 \mathrm{~Hz}, 291 \mathrm{~Hz}$, and $252 \mathrm{~Hz}$ in the detailed scheme. Generally, if the wheel axle is regarded as an elastic Euler-Bernoulli beam, the natural frequency is $10 \mathrm{~Hz}$ higher than that of the Timoshenko beam in both the simplified and detailed models. For the massless beam model with or without shearing stiffness, the natural frequencies increase by around $35 \sim 40 \mathrm{~Hz}$ with respect to that of the Timoshenko beam model. An interesting phenomenon also could be found that the axle shearing stiffness has caused the reduction of $6 \sim 7 \mathrm{~Hz}$ in the natural frequency by comparing the results from Mless-B and Mless-BwS models. Focusing on the Euler-Bernoulli and Timoshenko beams, the three-segment axle model (simplified scheme) may lead to the natural frequency difference of $5 \mathrm{~Hz}$ with respect to the nine-segment axle model (detailed model). As for the massless beams, the number of axle dividing segments has no effect on the natural frequencies. The mode shape is further solved and compared in Figure 12, which can be regarded as the resultant motion of bending and shearing motions. The mode shapes have not changed significantly for different modeling methods.

In the solution curve, the 3rd-order bending frequency is tried to be searched in Figure 13. However, if the wheel axle is simulated by the massless elastic beams, the fourth zero solution cannot be found. On the contrary, the Euler-Bernoulli and Timoshenko beams with the vibrating mass can reflect a higher modal frequency. For instance, the natural frequencies of the EB model in simplified and detailed schemes reach $612 \mathrm{~Hz}$ and $609 \mathrm{~Hz}$, respectively. For the Timoshenko beam model, the corresponding frequencies decrease to $550 \mathrm{~Hz}$ and $545 \mathrm{~Hz}$. Viewed from the mode shape, as shown in Figure 14, both types of beams have the similar mode shapes. In the simplified and detailed schemes, the mode shapes of the Timoshenko beam model are 15\% and $11 \%$ lower than that of the Euler-Bernoulli beam model, respectively.

6.2. Solution of Torsional Vibration Modes. In addition, the torsional vibration characteristics of the wheelset modelled by flexible axles with and without the vibrating mass are compared. Referring to equations (30)-(32), the transfer matrix and corresponding eigen equations can be obtained to solve the natural frequencies and vibration modes. Under free boundary conditions, the solution curves are given in Figure 15 , where $A(B)$-mass and $A(B)$-mless represent the flexible axle with and without the vibrating mass. $A$ and $B$ are 


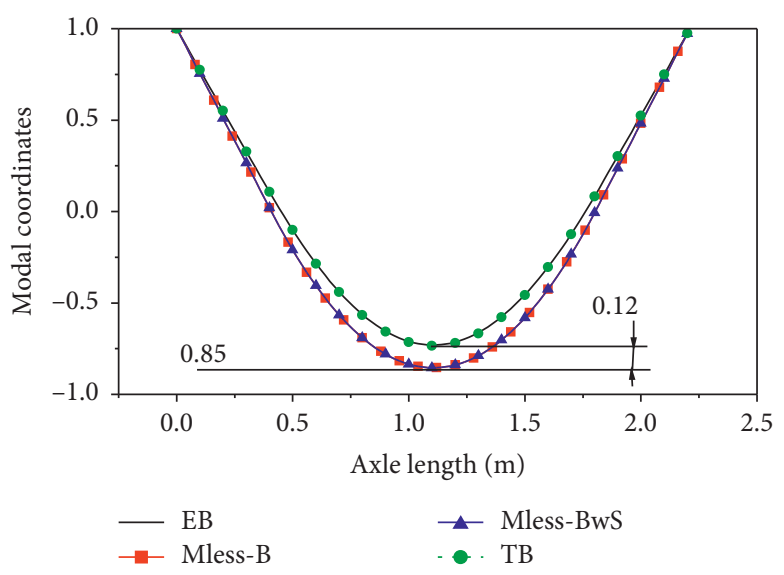

(a)

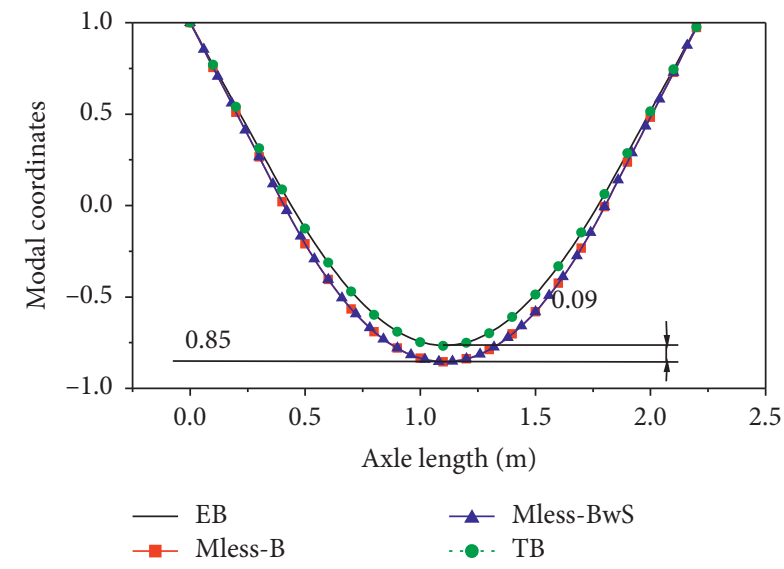

(b)

Figure 10: Mode shapes of 1st-order bending for different modeling schemes. (a) Simplified model. (b) Detailed mode.

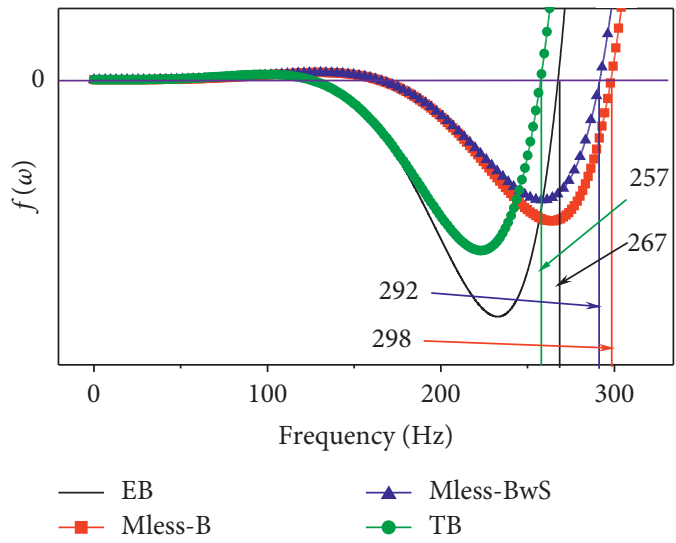

(a)

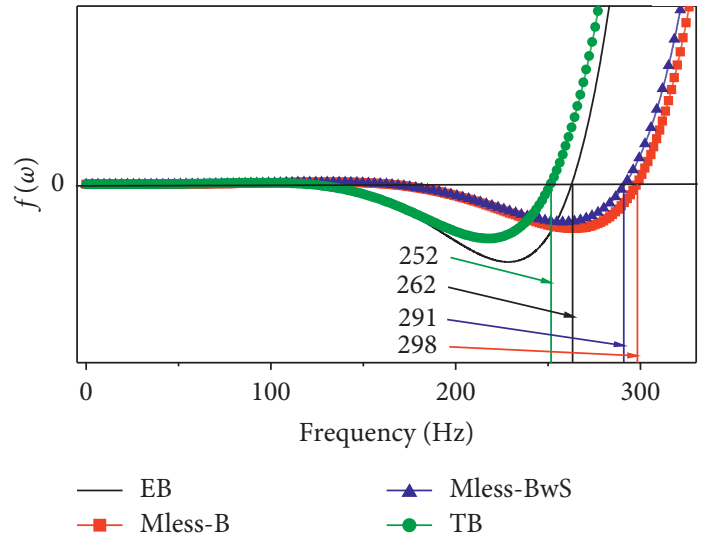

(b)

FIGURE 11: Solution curves of 2nd-order bending for different modeling schemes. (a) Simplified model. (b) Detailed mode.

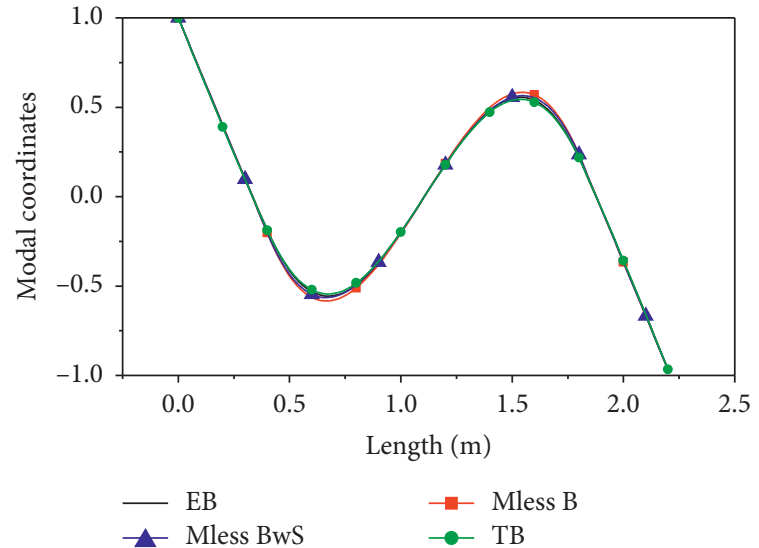

(a)

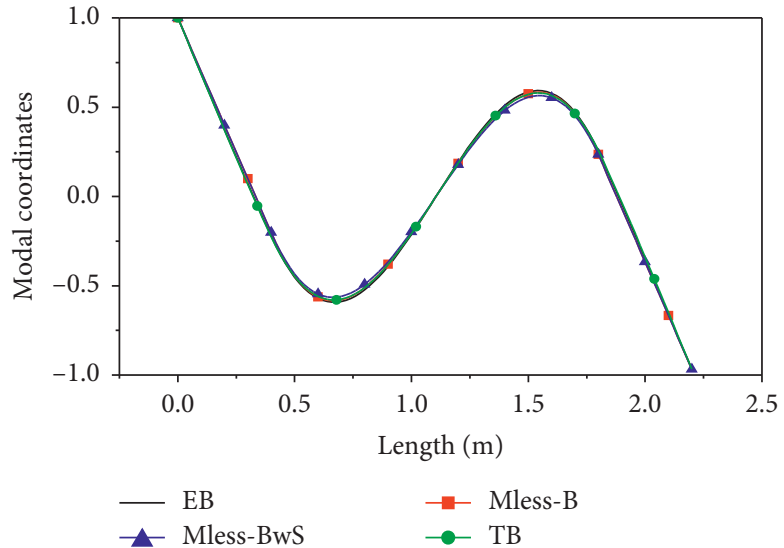

(b)

Figure 12: Mode shapes of 2nd-order bending for different modeling schemes. (a) Simplified model. (b) Detailed mode. 


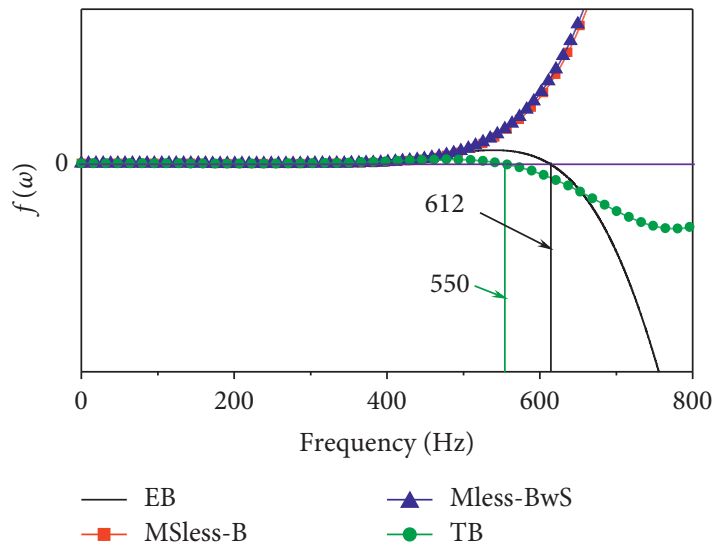

(a)

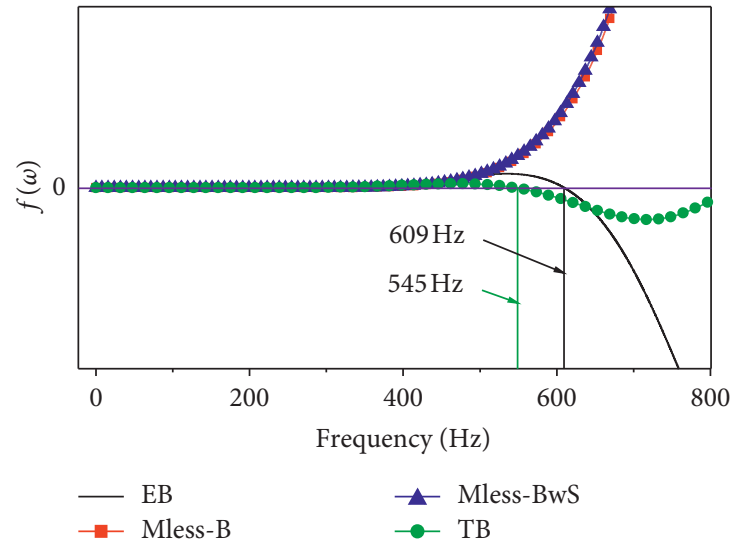

(b)

Figure 13: Solution curves of 3rd-order bending for different modeling schemes. (a) Simplified model. (b) Detailed mode.

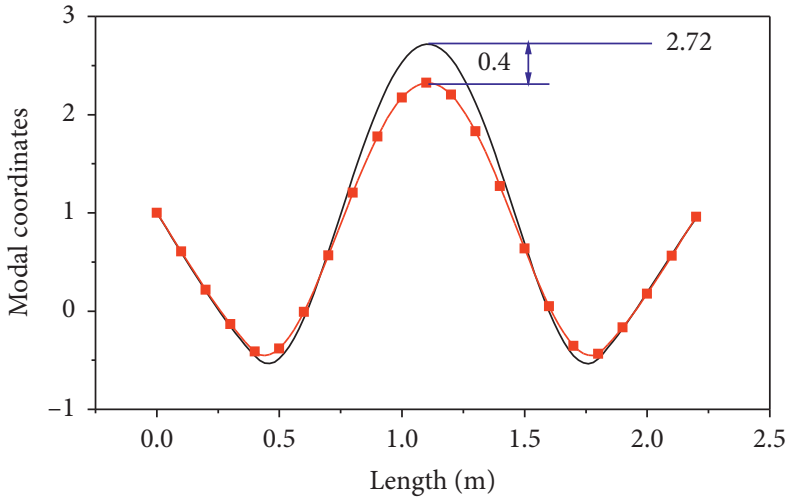

$-\mathrm{EB}$

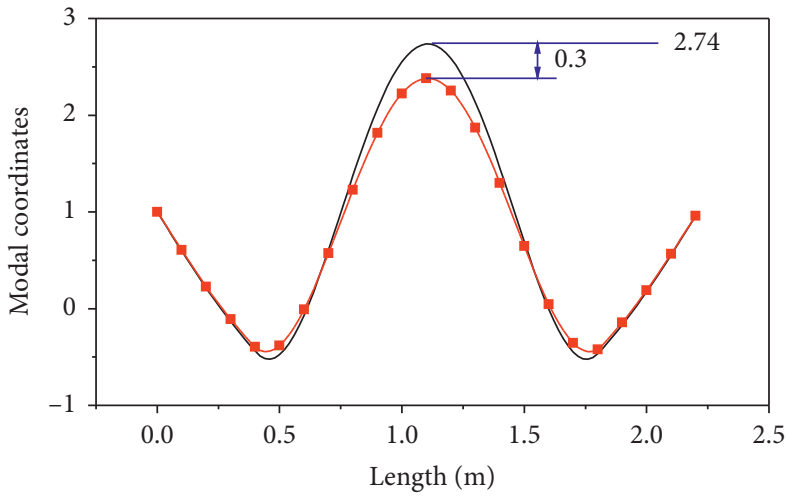

- EB

(a)

(b)

FIGURE 14: Mode shapes of 3rd-order bending for different modeling schemes. (a) Simplified model. (b) Detailed mode.

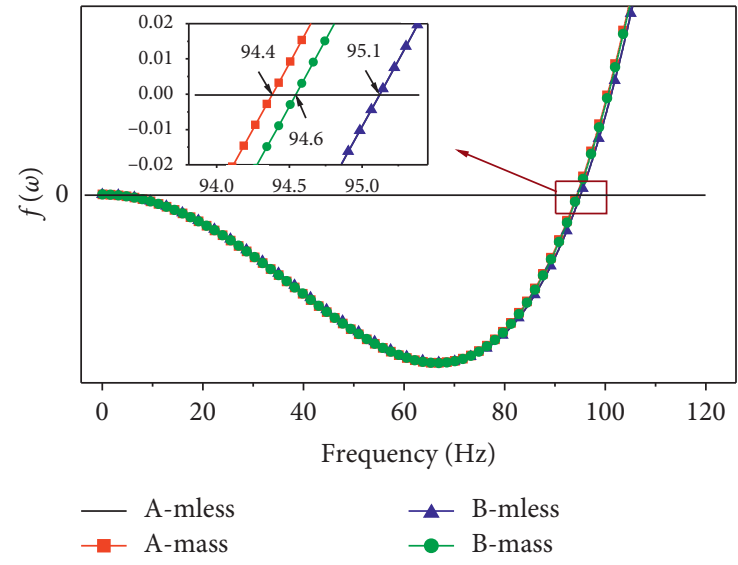

(a)

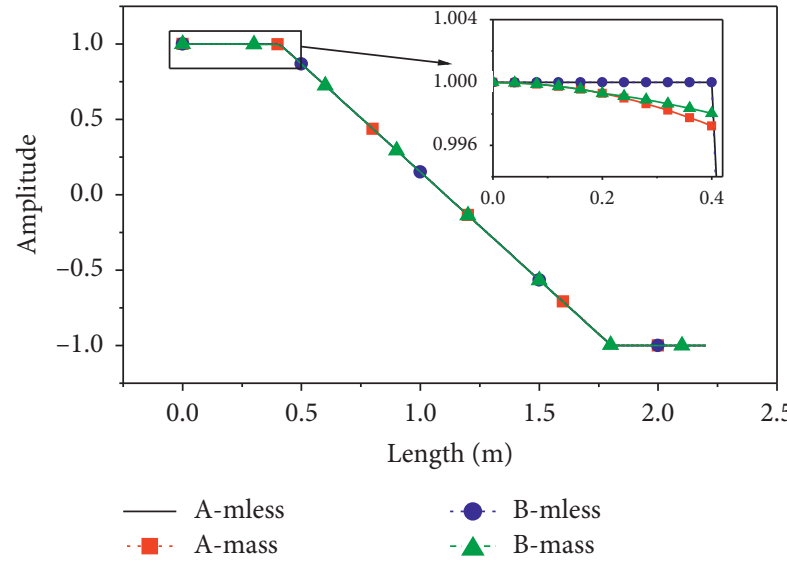

(b)

FIGURE 15: Natural torsional vibration characteristics. (a) Solution curve. (b) Mode shape. 
the simplified and detailed schemes. The natural frequencies of different models are almost the same, around $95 \mathrm{~Hz}$. For the mode shapes, the general deformations are present as the relative reverse torsion between two wheels. Obviously, the torsional modes for different models are almost coinciding with each other. Therefore, the flexible property of the axle mainly determines the natural vibration characteristics rather than the axle vibrating mass.

\section{Validation of Wheelset Natural Vibration Characteristics}

To verify the accuracy of the wheelset transfer matrix models, a detailed FE model of the wheelset is established with the solid element in ANSYS, as shown in Figure 16. The corresponding material properties are in accordance with those in Table 1 . The element size is limited to $2 \mathrm{~cm}$ so that the FE model has good accuracy to reflect the elastic modes. The Block Lanczos method is used to solve the vibration modes. For the wheel-axle contact, the surface-to-surface contact is simulated by the contact elements (contact174), whilst the penalty function method is used to solve the contact problem.

Using free boundary conditions, the modal parameters are calculated. Within the frequency range of $500 \mathrm{~Hz}$, the bending modes and torsional modes can be found. For instance, 1st-, 2nd-, and 3rd-order bending vibration occur at $116 \mathrm{~Hz}, 245 \mathrm{~Hz}$, and $501 \mathrm{~Hz}$, respectively. The mode shapes agree well with the results calculated by transfer matrices (Figures 9-15). In the same way, the displayed reverse torsional vibration of two wheels represents the 1storder torsional mode of the wheelset, which is reflected at the natural frequency of $98 \mathrm{~Hz}$.

According to the test and simulation results of the similar wheelset in [26, 27], the 1st-order and 2nd-order bending modes correspond to frequencies of around $120 \mathrm{~Hz}$ and $260 \mathrm{~Hz}$, which validate the numerical solutions to some extent. The accuracy of natural frequencies for the transfer matrix can be evaluated by comparing with the FE results in Figure 17. The results are presented in the forms of frequency and difference percentages. For the 1st-order bending vibration, the modeling method of the flexible axle with the mass has higher precision in numerical solutions. In the simplified model, the natural frequency error of the Timoshenko beam and Euler-Bernoulli beam with respect to the exact solutions can be limited to $6.9 \%$ and $8.6 \%$, respectively, whilst those in the detailed model reach $3.4 \%$ and $6 \%$, respectively. However, the modeling method of the massless elastic beam may produce the frequency error as high as $40.5 \%$. Definitely, the reasonable simplification of the wheelset model can obtain a higher solution precision.

For the 2nd-order bending mode of the wheelset, it has the same rule as reflected in Figure 18. The numerical results of the Timoshenko beam are most closest to the solution of the FE model, with frequency errors of 4.9 and $2.5 \%$ for the simplified and detailed models, respectively. Comparatively, for the Euler-Bernoulli beam, the frequency differences increase to $9 \%$ and $7 \%$, respectively, for the simplified and detailed models. In the massless beam system (Mless-B and Mless-Bws), the frequency error could even reach 19\% 22\%, when the axle shearing stiffness could narrow the natural frequency difference by $3 \%$. For the 3rd-order bending mode frequency, as compared in Figure 19, the Timoshenko beam models in the simplified and detailed schemes might overestimate the main frequency by $9.8 \%$ and $8.8 \%$, respectively. The frequency error of the Euler-Bernoulli beam model reaches around $22 \%$, no matter the model is established in detail or simply.

As for the torsional mode shown in Figures 15 and 20(d), the natural frequency difference between TMM and the FE model is about $3 \%$. In general, the combined model of the massless beam and rigid wheel can result in a large frequency error over $20 \% \sim 40 \%$ compared to FE solutions. On the contrary, both the Timoshenko beam and Euler-Bernoulli beam could achieve higher solving accuracy, and the natural frequency difference for bending modes can always be kept below 22\%. Particularly for the Timoshenko beam, the frequency error is less than $10 \%$. The wheel axle vibrating mass has the more significant effect on wheelset bending vibration than its shearing stiffness. The more axle segments of the wheel axle are divided, the higher the accuracy can be obtained. From another perspective, the torsional shearing stiffness of the wheel axle determines the torsional vibration characteristics of the wheelset, while the vibrating mass of the wheel axle has slight influence.

Finally, the computational efforts are studied by comparing the computing times of different models, as shown in Table 2. It can be found that, the FE model and TMM model, respectively, may spend 12.5 minutes and $2.5 \sim 3 \mathrm{~s}$ to calculate the natural vibration characteristics. In the TMM model, the global transfer matrix of the system is obtained by successively multiplying the transfer matrices of wheelset components. Therefore, the matrix dimension has not been changed with the number of components. That is the reason why the computing times of the simplified model and detailed model are close to each other. By using the low-order transfer matrices, the computational efficiency has been improved greatly.

In summary, for the TMM model of the wheelset, the computational time difference between different models is only below $0.3 \sim 0.4 \mathrm{~s}$ as compared in Table 2 . The computational efforts for simplified and detailed models are close to each other, so it is recommended that the wheelset should be modelled in the detailed way to ensure the solving accuracy. The relevant transfer matrices can also be used flexibly in research of the axle-type part vibration of railway vehicles. 


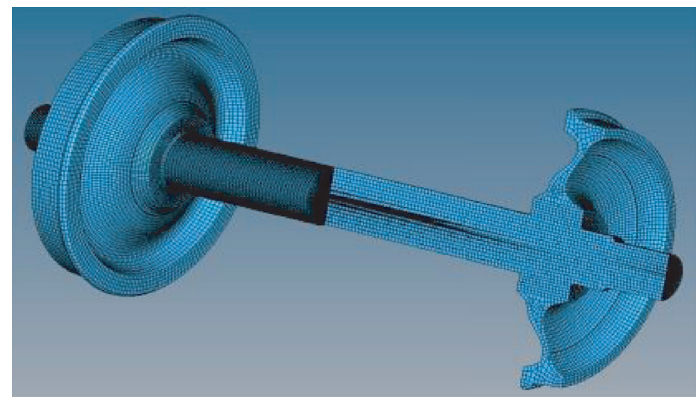

FIGURE 16: FE model of the wheelset.

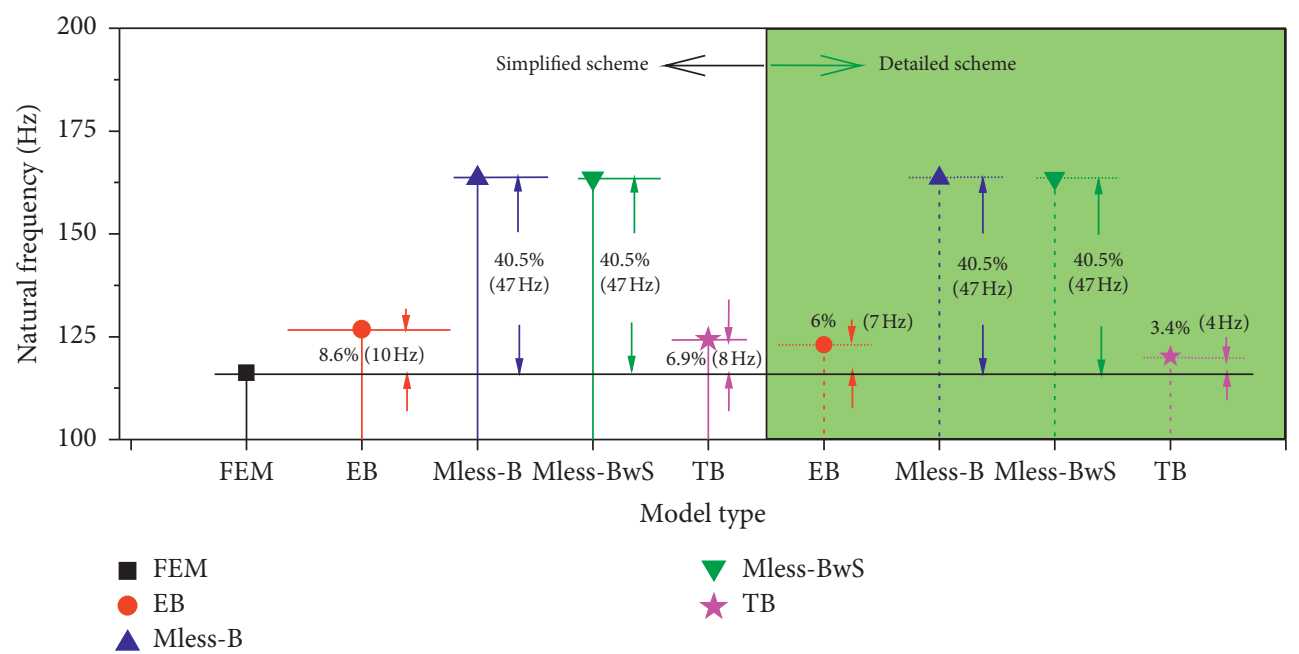

Figure 17: Modal frequency comparison of the 1st-order bending mode between TMM and FE method.

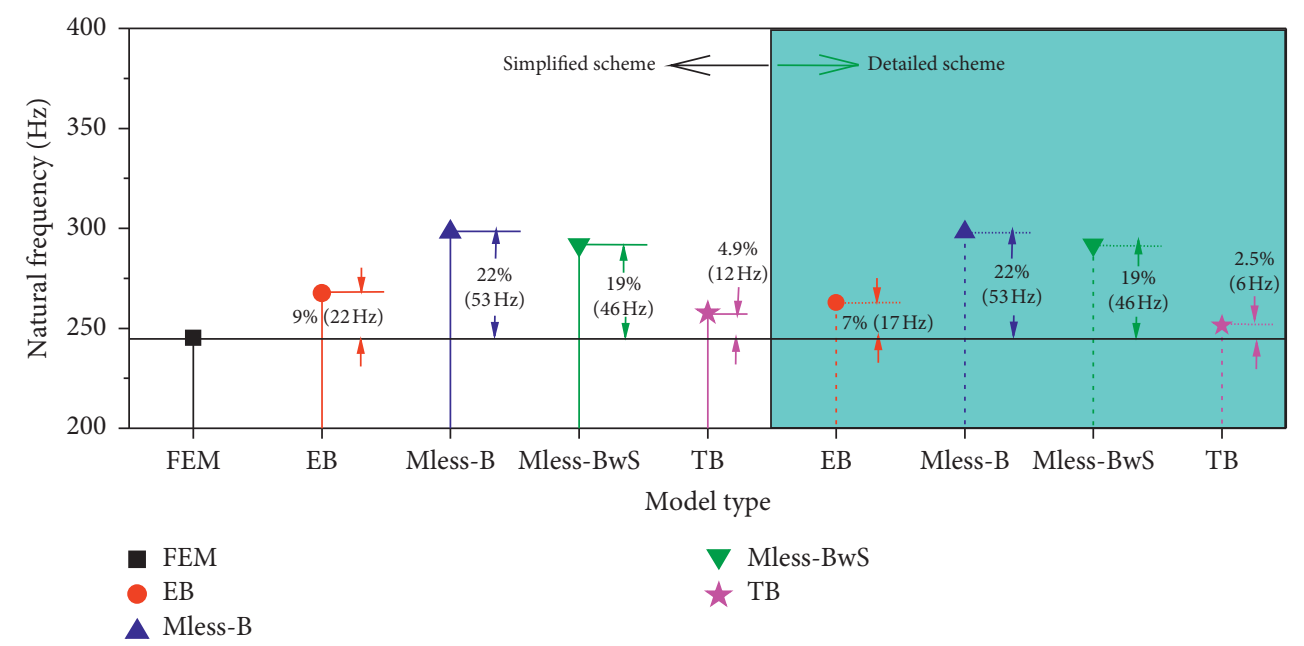

FIGURE 18: Modal frequency comparison of the 2nd-order bending mode between TMM and FEM. 


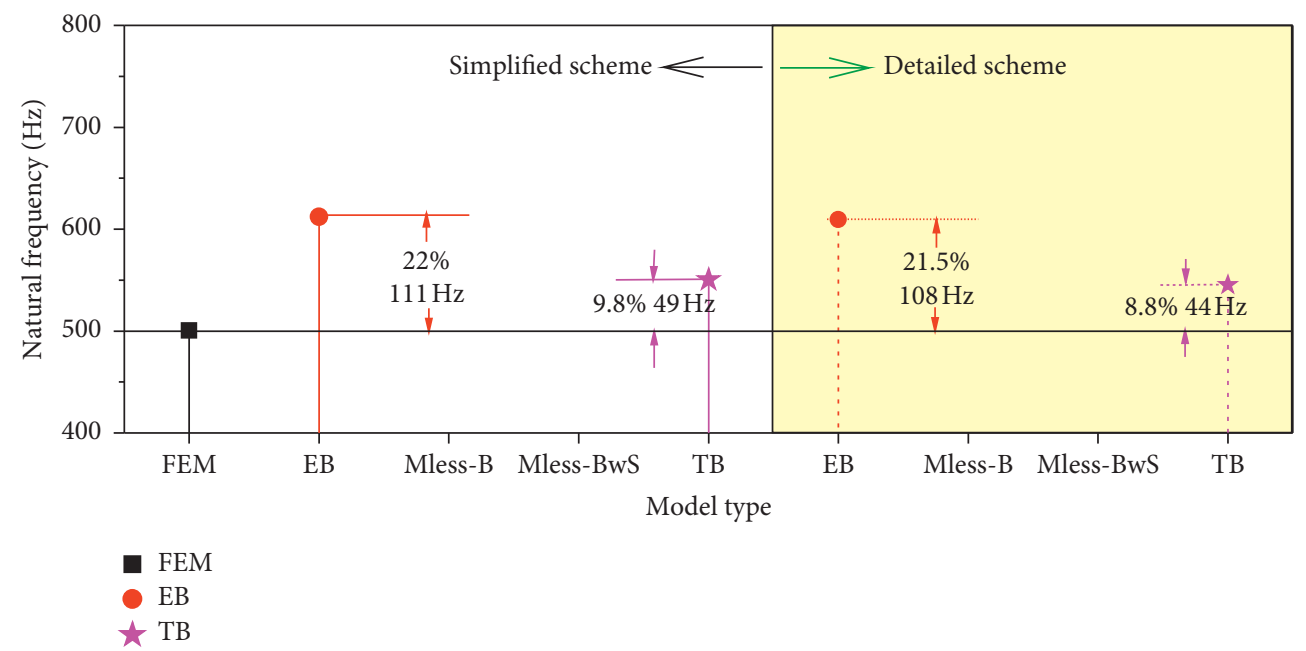

FIGURE 19: Modal frequency comparison of the 3rd-order bending mode between TMM and FE model.

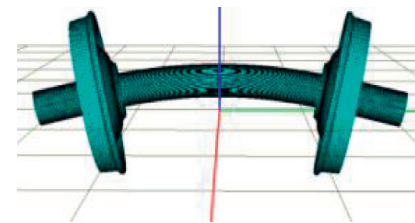

(a)

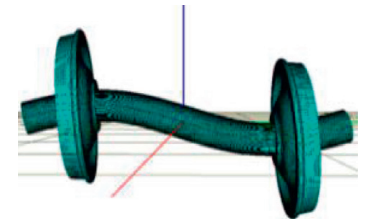

(b)

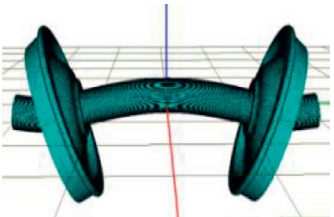

(c)

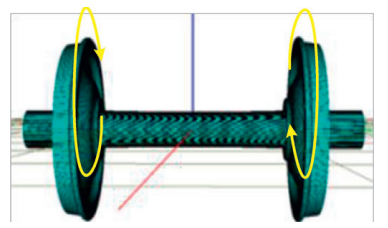

(d)

Figure 20: Bending and torsional modes of the wheelset solved by the FE model. (a) 1st-order bending: $116 \mathrm{~Hz}$. (b) 2nd-order bending: $245 \mathrm{~Hz}$. (c) 3rd-order bending: $501 \mathrm{~Hz}$. (d) Torsional: $98 \mathrm{~Hz}$.

TABLe 2: Computing times of different models.

\begin{tabular}{|c|c|c|c|c|c|c|c|c|}
\hline \multirow{3}{*}{$\begin{array}{l}\text { FE model } \\
12.5 \mathrm{~min}\end{array}$} & \multicolumn{4}{|c|}{ TMM simplified model } & \multicolumn{4}{|c|}{ TMM detailed model } \\
\hline & $\mathrm{EB}$ & Mless-B & Mless-BwS & $\mathrm{TB}$ & $\mathrm{EB}$ & Mless-B & Mless-BwS & $\mathrm{TB}$ \\
\hline & $2.6 \mathrm{~s}$ & $2.5 \mathrm{~s}$ & $2.5 \mathrm{~s}$ & $2.7 \mathrm{~s}$ & $2.8 \mathrm{~s}$ & $2.6 \mathrm{~s}$ & $2.6 \mathrm{~s}$ & $2.9 \mathrm{~s}$ \\
\hline
\end{tabular}

\section{Conclusions}

The elastic vibrating model and mode parameters of the wheelset are solved based on the transfer matrix method. The wheel axle with multidiameters contributes to the main elastic deformation, which is simulated by four types of elastic beam models including the Euler-Bernoulli beam, Timoshenko beam, elastic beam without mass and shearing stiffness, and the massless elastic beam with shearing stiffness. The modes of both bending and torsional vibrations are compared with the results of a FE model. Key conclusions are drawn as follows:

(1) If the wheel axle is modelled by the Euler-Bernoulli or Timoshenko beam, the natural frequencies of the bending mode of the flexible wheelset can be reflected accurately. Generally, the frequency difference between the transfer matrix and FE results can be limited below $22 \%$ and $10 \%$ for the Euler-Bernoulli and Timoshenko beam models, respectively. If the vibrating mass of the axle is not considered, the frequency error can reach $20 \% \sim 40 \%$, no matter the axle shearing stiffness is considered or not. Also, in this case, the bending mode with higher order cannot be obtained.

(2) For the torsional vibration of the wheelset, there is a slight difference between the results of flexible axle models with and without the vibrating mass. The natural vibration frequency error between the transfer matrix model and FE model is about 3\%. Both the torsional stiffness and wheel inertia influence its natural frequencies, while it has little relations with the rotational inertia of the axle.

(3) For the detailed and simplified modeling schemes, the natural frequency solving accuracy of the former is $3 \%$ higher than that of the latter. More flexible axle segments divided means higher solving accuracy. The computational effort of the transfer matrix model is much lower than that of the FE model, which can be attributed to the low and invariant dimension of transfer matrices, whether in the simply or complex models.

(4) The applicable conditions of different elastic beam models in wheelset modal analysis are revealed. The 
TMM may provide a convenient solution for modal analysis of the railway vehicle rigid-flexible coupling system.

\section{Data Availability}

The data used to support the findings of this study are available from the corresponding author upon request.

\section{Conflicts of Interest}

The authors declare that they have no conflicts of interest.

\section{Acknowledgments}

This work was supported by the National Natural Science Foundation of China (Grant nos. 52072249, 11790282, and 12072208), and Self-Determined Project of State Key Laboratory of Mechanical Behavior and System Safety of Traffic Engineering Structures (Grant no. ZZ2021-10).

\section{References}

[1] Y. Sato, A. Matsumoto, and K. Knothe, "Review on rail corrugation studies," Wear, vol. 253, no. 1-2, pp. 130-139, 2002.

[2] H. Y. Zhu, H. T. Hu, B. C. Yin, P. B. Wu, J. Zeng, and Q. Xiao, "Research progress on wheel polygons of rail vehicles," Journal of Traffic and Transportation Engineering, vol. 20, no. 1, pp. 102-119, 2020.

[3] Y. Q. Sun and S. Simson, "Wagon-track modelling and parametric study on rail corrugation initiation due to wheel stick-slip process on curved track," Wear, vol. 265, no. 9-10, pp. 1193-1201, 2008.

[4] G. Shen, X. H. Zhang, and M. H. Guo, "Theoretical study on rail corrugation on curved track of metro systems," Journal of Tongji University (Natural Science), vol. 39, no. 3, pp. 381-384, 2011.

[5] G. X. Chen, Z. R. Zhou, H. Ouyang, X. S. Jin, M. H. Zhu, and Q. Y. Liu, "A finite element study on rail corrugation based on saturated creep force-induced self-excited vibration of a wheelset-track system," Journal of Sound and Vibration, vol. 329, no. 22, pp. 4643-4655, 2010.

[6] G. X. Chen, X. L. Cui, and K. Wang, "Generation mechanism for polygonalization of wheel treads of high-speed trains," Journal of Southwest Jiaotong University, vol. 51, no. 2, pp. 244-250, 2016.

[7] J. Martínez-Casas, E. D. Gialleonardo, S. Bruni, and L. Baezal, "A comprehensive model of the railway wheelset-track interaction in curves," Journal of Sound and Vibration, vol. 333, no. 18, pp. 4152-4169, 2014.

[8] A. Guiral, A. Alonso, and J. G. Giménez, "Vehicle-track interaction at high frequencies-modelling of a flexible rotating wheelset in non-inertial reference frames," Journal of Sound and Vibration, vol. 355, no. 27, pp. 284-304, 2015.

[9] I. Kaiser, G. Poll, and J. Vinolas, "Modelling the impact of structural flexibility of wheelsets and rails on the wheel-rail contact and the wear," Wear, 2020, In press.

[10] B. Peng, S. Iwnicki, P. Shackleton, D. Crosbee, and Y. S. Zhao, "The influence of wheelset flexibility on polygonal wear of locomotive wheels," Wear, vol. 432-433, Article ID 102917, 2019.
[11] I. C. Cruceanu and S. Sorohan, "Determination of the harmonic response of a railway wheelset using the finite element analysis method," Procedia Manufacturing, vol. 46, pp. 173179, 2020.

[12] L. Baeza, J. Giner-Navarro, D. J. Thompson, and J. Monterde, "Eulerian models of the rotating flexible wheelset for high frequency railway dynamics," Journal of Sound and Vibration, vol. 449 , no. 9, pp. 300-314, 2019.

[13] D. Fourie, R. Fröhling, and S. Heyns, "Railhead corrugation resulting from mode-coupling instability in the presence of veering modes," Tribology International, vol. 152, Article ID 106499, 2020.

[14] B. Ding, G. Squicciarini, D. Thompson, and R. Corradi, "An assessment of mode-coupling and falling-friction mechanisms in railway curve squeal through a simplified approach," Journal of Sound and Vibration, vol. 423, pp. 126-140, 2018.

[15] J. Giner-Navarro, J. Martínez-Casas, F. D. Denia, and L. Baeza, "Study of railway curve squeal in the time domain using a high-frequency vehicle/track interaction model," Journal of Sound and Vibration, vol. 431, pp. 177-191, 2018.

[16] N. Xu, Z. S. Ren, and S. Ma, "Vibration analyses of elastic wheelset model with concentrated mass and moment of inertia," Journal of Mechanical Engineering, vol. 50, no. 2, pp. 125-131, 2014

[17] M. Arai, S. Kuroda, and K. Ito, "Static elastic-plastic analysis of a pipe structure by the transfer matrix method," Journal of Pressure Vessel Technology, vol. 143, no. 1, Article ID 011801, 2021.

[18] J. W. Lee and J. Y. Lee, "Free vibration analysis of a rotating double-tapered beam using the transfer matrix method," Journal of Mechanical Science and Technology, vol. 34, no. 7, pp. 2731-2744, 2020.

[19] T. Bakeer, "Assessment the stability of masonry walls by the transfer-matrix method," Engineering Structures, vol. 110, pp. 1-20, 2016.

[20] H. Zhang, X. T. Rui, F. F. Yang, and G. L. Chen, “The adaptive estimating method and simulation used for the vibration frequency of the system of missile," Journal of Vibration and Shock, vol. 36, no. 10, pp. 212-216, 2017.

[21] W. M. Zhai, Vehicle-track Coupled Dynamics: Theory and Applications, Springer, Berlin, Germany, 2020.

[22] P. Liu, W. Zhai, and K. Wang, "Establishment and verification of three-dimensional dynamic model for heavy-haul traintrack coupled system," Vehicle System Dynamics, vol. 54, no. 11, pp. 1511-1537, 2016.

[23] Tb/T 1010-2016, Wheelset and Bearing of Railway VehiclesTypes and Basic Dimensions, National Railway Administration of the People's Republic of China, Wuhan, China, 2016.

[24] W. T. Thomson and M. D. Dahleh, Theory of Vibration with applications, Prentice-Hall, Hudson County, NJ, USA, 5th edition, 1997.

[25] X. T. Rui, L. F. Yu, Y. Q. Lu, B. He, and G. P. Wang, Transfer Matrix Method of Multibody Systems and its applications, Science Press, Beijing, China, 2008.

[26] C. L. Zhao and X. L. Dou, "Modal testing and simulation verification of rail vehicle wheelset," Open Journal of Transportation Technologies, vol. 9, no. 3, pp. 150-158, 2020.

[27] J. R. Hu, B. G. Wang, and L. M. Zhang, "Modal analysis method for damage wheelset diagnosis," Journal of Transportation Engineering and Information, vol. 5, no. 3, pp. 8589, 2007. 